\title{
Principles of interpretation, tourism and heritage interpretation - the experience of Romanian museums
}

\author{
Daniela Dumbraveanu*, Ana Craciun, Anca Tudoricu
}

University of Bucharest, Romania

This paper aims to present a generic theoretical framework related to interpretation as a field of study focusing on tourism interpretation and heritage interpretation. It primarily focuses on discussing the international evolution of this field and the principles of interpretation as presented by their author, Freeman Tilden. Secondly, the paper attempts to analyze to what extent modern interpretation is experienced in Romania by means of two relevant case studies selected. The two case studies selected are significant and symbolic institutions within their system, well known and internationally visited: the Peasant Museum in Bucharest and the Memorial to the Victims of Communism and to the Resistance in Sighetu Marmatiei. Thirdly, the paper draws a broader picture showing whether the principles of interpretation and heritage interpretation are familiar to Romanian museums and to what extent they are in use.

Key Words: interpretation, tourism, visitor's needs, principles of interpretation, Tilden, museum interpretation, heritage interpretation.

Article Info: Received: December 10, 2015; Revised: April 21, 2016; Accepted: May 8, 2016; Online: June 4, 2016.

\section{Interpretation as a cross-disciplinary field of study}

Interpretation is the cognitive process underlying the composition of reality, as each person perceives it. Individuals have a personal capacity of interpretation that serves their needs and interests. In other words, the individual is present in his interpretation by means of coherence (Tilden, 1967), which defines itself regardless of the information transmission channel. Basically, raw data is received, interpreted and conveyed through a codified language consisting of a set of validated symbols and related to the inner and outer world. The reaction

\section{* Corresponding author}

Address: University of Bucharest, Faculty of Geography, 1 Nicolae Balcescu Avenue, 010041, Bucharest, Romania.

Phone: +40213153074| Email: daniela.dumbraveanu@humangeographies.org.ro 
to external stimuli represents the perception of an object, phenomenon or situation. Before perception, there is the sensation, which is defined as a passive process of receiving information from the external environment by the subject perceiving the stimuli. Thus, mere exposure to external sensory information requires no cognitive effort from the person concerned.

Perception does not have a universally accepted definition. Most experts agree that it is a process that occurs predominantly at sensory level, following the "collaboration and influencing of the senses," being equally "the result of the reciprocal influences that objects or qualities thereof exert on one another (Rotila, 2004).”

Along with sensation, perception and representation, interpretation too is an important step in processing information as part of the communication process (Coren, 2003). Perception does not consist merely in receiving sensory information, but also in selecting, organising and interpreting information received through the sensory organs, and it is often defined as a "translation" of said information. It is, namely, a phase in which perception makes meaning of the stimuli, thus constituting the essential element of the next phase: that of representation. Representation based on perception calls upon all the experiences and information accumulated up to that moment, for it is being carried out in the area of knowledge of the individual who performs a mental projection according to the information it has (Urry and Larsen, 2011).

One cannot represent elements or situations that do not relate to something known to the individual. Even if the information is new and raw, by means of representation one attempts to translate, to assign meaning, by creating connections with previous experiences. The interpretation process is the 3rd phase of the entire circuit, though to some extent included in both perception and representation. If perception interprets sensation, interpretation encompasses both sensations and perceptions and ascribes them significance depending on the context, as it is a process that takes place at macro level. However, human mind does not process all the information received from the outside, instead it makes a selection, depending on the individual's personal motivations.

The concept of "interpretation" is often used to mean "translation," in fact in English the term "interpreter" is used instead of "translator" (Oxford Dictionaries, 2016) to designate the person who mediates communication between two individuals that use a set of different symbols in order to communicate. The term is also used in the arts, by actors or artists. Interpretation itself is not limited to deciphering a set of symbols, rather it appeals to the vision of the person making it, through which a series of messages are sent, as well as to the individual's ability to adapt the message for it to be perceived by a specific target segment (Gadamer). Relating to the discussion partner or the audience is important in an educational process (Gallagher, 2004).

Consequently, in order for the interpretation process to take place, three important segments are required: addresser, the material subject to interpretation (text, object, etc.) and the recipient. Basically, everything we know is an interpretation in one way or another, since what people consider knowing is in fact a narrow vision of things, which is typical of the human being and 
generated only through collective memory. More often than not, the communication process does not focus on the actual interpretation, but rather on its product, or on the information conveyed by an individual and received by another. The high importance of the interpretation process lies in the fact that people act according to what they know. The interpretation of a piece of information dictates the individual's attitude towards a certain subject, it changes previous perceptions, it creates a set of values according to such perceptions and spreads among other people values and beliefs which the individual has learnt to endorse (Chenari, 2009). It is an attitude manifested any time in any field.

\section{The evolution of interpretation as concept and field}

Interpreting is available to everybody; the concept takes on additional features and a special importance when the intention behind it is to trigger certain attitudes or states among those receiving the message. In the arts, the addresser may be an actor or group of actors, a curator, a musical artist, a plastic artist, whereas the recipient is the audience or all the people receiving the message in question. The way the message is conveyed, the elements used, the personal charm, all of these are part of a set of symbols that the addresser uses in order to trigger a reaction while expressing ideas with which he himself resonates.

In heritage interpretation, behind every addresser there is an institution that he serves and that is present in the collective memory. In this context, interpretation applied at various levels has a particular importance, since it is a tool able to explain, animate or trigger highly emotional reactions. In tourism, it originally appeared in the native areas of the US in the mid 19th century, against the backdrop of the nature conservation movement existing at that time on the Continent. However, the concept as such did not exist, and interpretation as it is known today overlaps with the education process due to the need that the US population become aware of the importance of natural elements and the environment and protect them (Tilden, 1967). The efforts of prominent personalities of the time, such as Ralph Waldo Emerson, David Thoreau, John Muir or Enos Mills, promoters of the initiative, who dedicated their entire activity to this endeavour, culminated in the emergence of the concept of "national park." It was John Muir, a conservationist, who coined the term "interpretation” in tourism in 1871 (Thorsten Ludwig, 2003).

Basically, this was the period when the most famous popular parks appeared on the North American continent: Yosemite National Park and Rocky Mountain National Park (Parks and Association, 1988). This was the moment when the first schools of interpretation emerged. However, the most important achievement that would later help develop the field of interpretation was the creation in 1916 of the National Park Service (NPS), an institution that currently coordinates all the activities carried out in the US natural and national parks. While in those years the phrase "park interpretation" designated all the activities carried out in those areas, as of 1957 it relates directly to visitors and represents all the methods by which a message is conveyed to the audience (Ham, 2013). This was possible thanks to the American journalist Freeman Tilden, who 
founded the science of interpretation and established a series of principles of interpretation for experts from protected areas with the aim of providing a unique experience to visitors. Later on, apart from being entities responsible for protecting nature, national parks became major tourist attractions, so that experts focused both on the quality of the information provided and on the manner in which it is conveyed to the public. As a result, protected natural areas are currently considered providers of well-structured educational programs and responsible for creating a pleasant environment. They feature thematic paths and trails, lookout points signalled with a variety of interpretive panels, and host educational programs to attract the interest of those present (Tilden, 1967).

The institutional framework is evolving, all the more so since tourism is a useful tool in the awareness and protection process, as well as economically. The protection of the natural heritage has been a concern both tangible and intangible (especially in the last decades).

At the same time, apart from the institutions in charge of protecting natural and cultural areas, such as the United Nations Educational, Scientific and Cultural Organization (UNESCO) or the International Council on Monuments and Sites (ICOMOS), in the protected areas there are centres or departments for interpretation dedicated to training the staff. Also, various associations or NGOs offer such courses to specialised staff: the European Association for Heritage Interpretation (Interpret Europe), the Scottish Association for Interpretation (Interpret Scotland), the Australian Association for Interpretation (Interpret Australia) and the National Association for Interpretation (NAI). All these institutions have one common goal: to preserve heritage and develop different interpretation strategies, even though most of them use the principles of interpretation laid down by Freeman Tilden as a framework. Currently, the role of interpretation switches from the need to preserve to the visitor's need of visibility and provocation, so that attention is directed from the protected natural areas to the cultural institutions with tourism value.

As it was the case with protected natural areas, museums, historic and archaeological sites are institutions dedicated mainly to protecting cultural heritage and raising awareness among target groups on the importance of the exhibits presented. Museums experience the most acute need for change in addressing educational programmes, especially for economic reasons. In spite of the fact that cultural institutions and, in particular, museums, are regarded as institutions dedicated to teaching rather than in their true economic dimension, they need resources to continue their work. Museums benefit to a very small extent from economic resources from the state, which forces them to look for other sources of funding. Furthermore, museums nationwide have lost popularity, due to their touch of "old;" this is due to the fact that the latest technologies make their way with difficulty into museum premises, but also to the fact that the activity programmes offered by museums are quite scarce and lack consistence (McCall and Gray, 2013). This economic shortage also affects the quality and size of the employed staff. Only a handful of museums are able to train their employees or send them in exchange programmes abroad.

In Romania, the body that mediates the relationship between local and national institutions and museums is the National Network of Romania Museums, which supplies advice on museum management and project 
management, while also supporting museums' endeavour to integrate in the national and international circuits. Another advantage of this institution is its affiliation to the Network of European Museum Organisations (NEMO), thanks to which museum employees have the opportunity to participate in programmes organised by the two institutions in partnership, programmes focusing on the good management of the activity of a museum, as well as in trainings for professionals working in museums.

Since there is no legal framework to certify the capacity of interpreter ("interpretor" in Romanian) and to create a concordance between institutions at European level, exchange programmes are less effective in the museum field (Tröndle et al., 2012). There are various international courses certifying interpreter training; however, the distinction between one function and another is not clear, due to the fact that the term itself is not typical of this field, although it caters to an internal need. More specifically, specialists have difficulty distinguishing between "museum programme assistant," "education specialist," "interpreter" or "guide." Oftentimes, they adapt their presentation depending on the field of activity of their conversation partner. The difficulty in distinguishing between guide, education specialist and interpreter lies in the shared duties of these positions, especially in Eastern European countries, where museum staff is often limited, which is why specialists are forced to exceed their duties.

In Romania, as regards the legal framework, heritage interpretation is a vague concept, expressed in general terms and it usually covers all the activities carried out in situ in the museum in relation to visitors. However, museum staff is mixed and consists, among others, of conservation specialists, researchers in charge of providing information (be they historians, biologists, etc.), museum educators and guides (Christopher Grisham, 2014). The name of "guide" is still widely preferred to refer to anyone who makes a transfer of information for educational purposes, from the institution to visitors. The need for an interpreter is currently not very obvious due to the fact that museums still maintain their classical perspective on the role they hold and on how information is transferred. The interpreter, as a person that should be primarily in charge of implementing various programmes and cultural activities (including as performer) and of managing them, is associated rather to galleries and private initiatives existing in the field of performing arts, where a part of these tasks are assigned to the curator. Nevertheless, under the impact of Western influence that brought upon a significant increase in alternative culture and private initiatives in the cultural field, museums increasingly feel the need to exercise their entertainment function in order to keep pace with the new wave. In this context, the need for an interpretation specialist can help reconsider the term "museum" as well as the role museums should undertake nowadays.

\section{Methodology}

This paper relies on a much broader study desing and methodolgy concerning interpretation with particular focus on museum interpretation in Romania as part of a Phd research venture. It therefore relates its findings on qualitative 
and quantitative methods, primary and secondary data. The results used in discussing and arguing the current interpretation aspects mostly issued by Tilden have resulted from extended and in depth structured intreviews with representatives of National Network of Romania Museums. Both target groups have been interviewed over a time spam of 4 years. Most of the interviews have been conducted face to face, recorded and transcribed. Some of the representatives after several interview sessions continued to be contacted for updating their views via e-mail with short structured questionnaires. Extended fieldwork at the, and within the premises of the case studies have been conducted mainly to observe, analyse and discuss interpretation aspects with both curators and visitors.

\section{Tilden's principles of interpretation}

Freeman Tilden became years ago a key figure in the field of interpretation and the ideas he expressed as guiding principles are just as actual and are being frequently adapted to the present day reality. Since its publication in 1957, the book "Interpreting our Heritage" was deemed by the specialist community in charge of protecting and preserving natural heritage the most important achievement in the field of environmental studies. Nowadays, it is the cornerstone in the interpretation of any type of heritage and it remains just as valid and impressive thanks to the accessibility of its language. Tilden's book became indispensable to any specialist due to the fact that it deals with general ideas, posited as principles, without the aim to provide solutions or recipes. The way in which the author has managed to capture the attention of and provoke readers is reflected in the very 6 principles that he considers essential in any interpretation programme. Through these principles, Tilden brings a change in perspective as regards the approach to natural and anthropogenic heritage, rendering it accessible and "translating" it to the general public for preservation. According to the first principle posited by Tilden, "Any interpretation that does not somehow relate what is being displayed or described to something within the personality or experience of the visitor will be sterile" (Tilden, 1967:11).

In order to understand, memorise and critically analyze a received message, the visitor must feel involved, so that the information provided complements the experience and knowledge already acquired. Visitors do not want to "listen to words," they want to be "spoken with" (Tilden, 1967:12). This is especially important for guided tours, given the interpersonal connection between the guide and the visitors. The importance of involving the visitor in the story created is also underlined by the fact that emotions are states that can be induced or controlled. Thus, a person's emotional experience arises to a great extent from the subjective interpretation of an event, rather than as a result of the event itself, regardless of whether the interpretation corresponds or not to its purpose (Heshmat, 2015).

The 2nd principle distinguishes between raw data and message. According to this principle, information as such is not interpretation. "Interpretation is revelation based upon information. But they are entirely different things. However, all interpretation includes information." (Tilden, 1967:18). Moreover, 
the information or communication process rarely uses sets of raw information, such as events that occurred at a certain point, scientific facts, laws, etc. Based on these, the people responsible for conveying the message bring their contribution to it, through their own personal experience and perception on the subject. The veracity and ethics of quality interpretation is based on a balanced mix of science and art (Beck and Cable, 2011). The tourism interpretation process is based on a scientific truth, which is decoded and contextualized so that each visitor may understand the message and filter it against their personal experience. Regardless of the visitors' level of education, they must be able to understand the message and use it further on. Tilden signals thereby that the interpretation process is interdisciplinary and it is more of an art than a science, it cannot be both things at the same time.

According to the author, interpretation is an art, which combines many arts, regardless of the type of materials to be processed (Tilden, 1967:26) ${ }^{1}$. The ultimate goal of interpretation is to provide a memorable experience rather than train at any cost. He believes that not everyone is capable of creation and artistic expression, but each person is endowed with the ability to receive art through their own senses and to understand it, which is why sending a message in this way is the best combination for training and impressing at the same time. For Tilden, the entertainment function is fundamental, all the more so since the experts are working with the visitors' leisure time. This need has been amplified in recent years, with the intense development of technology media, which at the same time generated the emergence of shopping centres that partly cover the consumers' cultural needs.

Perhaps the most important principle in Tilden's vision is the one that emphasizes the ultimate goal of the interpretation process. There are many ways to convey a message, yet the success or failure of the process and of the method chosen are reflected in the visitor's attitude and emotional state at the end of the visit. According to Tilden, "The chief aim of interpretation is not instruction, but provocation" (Tilden, 1967) ${ }^{2}$. Provocation involves from the very beginning another important task: that of capturing attention. This role that museums must undertake has been only recently applied, despite the fact that the idea and the need thereof were expressed years ago. Natural parks were originally "laboratories" where the process of training from teacher to students was encouraged based on the contact with the elements that were being talked about. Subsequently, natural parks as they are known today have become attractive based on the visitors' personal experience with the space in question, leaving the training process in the background and provoking visitors.

This is accomplished by offering a smaller amount of information, while combining different techniques to capture attention and connect to the visitors' prior experience, depending on their profile. In supporting the need to provoke and invite participation, an important aspect is the first hand experience, which highlights the importance of interaction between man and space, between man and object. In this way, the visitors experience a constant

\footnotetext{
${ }^{1}$ The $3 r d$ principle of interpretation is "Interpretation is an art, which combines many arts. Any art is in some degree teachable."

${ }^{2}$ The 4 th principle of interpretation
} 
feeling of satisfaction for discovering by themselves the story of the space or object by exploring it in situ. Such an approach, which is based on providing a unique experience instead of conveying information, stimulates the visitors to come back, so that they may attend a series of events meant to complement the information already acquired, through participatory techniques.

The 5th principle laid down by Tilden is perhaps the most comprehensive one, as it represents a combination of the four principles mentioned above. According to this principle, tourism interpretation should present a whole, rather than a part, should capitalize on the heritage through contextualization, regardless of the particular value of the exhibit, and should relate to the individual as a whole, this way encompassing the individual's interest in a specific problem ${ }^{3}$.

In his statement, Tilden used as arguments linguistic references. In English, the term "whole" was used in the sense of healthy, a term that has always been employed to define the general well-being of the body with all its functions, not just some of them (Tilden, 1967:40). A holistic approach to interpretation increases the capacity to understand and assimilate the message, while also strengthening the connection between the visitor and the space he is in, by underlining the importance of the place. The author starts from the assumption that, regardless of the initial intention behind their visit, tourists need to be informed about what is in that place. This need cannot be satisfied by a transfer of raw information on the subject/topic of the visit, but rather through an approach that brings the topic to the forefront by means of a message that once received would complement the information and experiences previously acquired. In this way, the visitor's interaction with the place brings back the process of knowing from the past into the present. Recently, amid an ever growing variety of cultural consumers and of the tourism market in general, this principle has been generating different reactions as to the purpose of cultural institutions and, in particular, of museums (Staiff, 2014).

While in the case of natural heritage the fundamental role of parks and nature reserves is to preserve, the role of cultural institutions and museums in particular fluctuates, due to the cultural context that encourages the focus on the visitors' needs. That is why, in the case of museums, tourism interpretation has a special dynamic and a specific morphology. Given the need to use tourism interpretation as accurately as possible, museums become living institutions that undergo a constant transformation. On the one hand, they represent cultural entities perceived as generating credible information; on the other, they should use tourism interpretation to educate, but also to attract visitors who will wish to return. Therefore, a basic relationship can be identified: the one between the role of museums and the visitors' attitude and expectations.

As a result of technological progress and, at the same time, of the fact that access to an overwhelming amount of information is easier than ever, visitors want to be involved in the story, but not at any price. Their need is not just to live a unique experience and benefit from processed (decoded and attractively "packed") information; instead they want to have the certainty that they are receiving accurate and comprehensive information, which could be double-

\footnotetext{
"Interpretation should aim to present a whole rather than a part. Interpretation is conceptual and should explain the relationships between things."
} 
checked by potentially consulting multiple sources (Hein, 2002). The possibility of an alternative, through the provision of a second version, of a second source, is a more recent need of consumers, as a result of the information overload to which they are exposed. The basic idea is: the approach must be addressed to the visitors, to their knowledge and experience. Since individual approach of visitors, in terms of facilities, interpretation equipment and guided tours, is difficult to achieve, it becomes increasingly important to know visitors and target audiences as accurately as possible in order to facilitate access to the programs carried out by each institution.

In outlining the main rules of interpretation, Tilden lays down a set of general guidelines, with a wide applicability, and he does not insist on the peculiarities of the visitors. However, in his sixth principle, Tilden argues that interpretation for children requires a different approach than interpretation for adults: "Interpretation addressed to children should not be a dilution of the presentation to adults, but should follow a different approach." (Tilden, 1967:47 $)^{4}$. The main differences consist in filtering and decoding the information conveyed, avoiding scientific rigor and specialised terms in favour of terms that are easier to understand. As regards children, Tilden emphasizes the preference for superlatives and the special sensory involvement that children manifest due to their need to touch, smell and interact with the object. This latter need is the main factor that has generated the most common form of children participation in cultural institutions, parks or museums: group visits. While in the past they were encouraged by both teachers and specialists, in recent years, as it was easy to anticipate and associate these visits with the formal environment typical of the present day education system, the enthusiasm which characterised such visits in the past is now diminished, the concentration capacity is lower, all the more so because museums, in their attempt to become after-school institutions, have failed in their attempt to be perceived as informal.

Following the process generated by Tilden in shaping interpretation as a field of its own, there were several other attempts to add content and to endow tourism interpretation with substantiality. Currently, tourism interpretation is tackled by experts from various fields who are trying to include in the scope of interdisciplinarity those features that provide its specificity. All these attempts take the form of case studies represented at micro-scale and most of them analyze the impact that certain methods have on a particular segment of the public. In this endeavour, an important role is played by the identity value and public perception of the institution in question, which gives rise to a certain type of expectations.

\section{Tilden's principles of interpretation and a Romanian sample experience}

In Romania, museums are still conservative when it comes to tourism interpretation, all the more so because there is no culture of studying consumer

${ }^{4}$ The 6 th principle of interpretation 
behaviour, and especially cultural behaviour, which could and should support the creation of specific programmes. Under these circumstances, the level of interpretation is determined by the identity value and reputation, as well as by the ability to attract funds to finance such programmes. One can distinguish two museums which, at interpretive level, show a different approach and manage to rank among the most visited museums in the country: the Romanian Peasant Museum in Bucharest and the Memorial to the Victims of Communism and to the Resistance, in Sighetu Marmatiei.

Case study: Romanian Peasant Museum and the Memorial to the Victims of Communism and to the Resistance

In the collective perception of the inhabitants of Bucharest, the Romanian Peasant Museum represents a strong element of identity, due to the fact that it brings to the forefront the peasant-hero, one of the few Romanian symbols whose image has not been altered over the years. The peasant-hero is portrayed in his living space and this way a part of the village is brought within the city. According to studies carried out in 2014, the museum is most often visited by people in the 18-24 and 35-49 age groups, that is young people and adults who regard the countryside as a space for reconnecting with oneself (Carmen Croitoru, Anda Becut, 2015).

Interpretation and museography are even today based on the '90s view of Horia Bernea, a prominent contemporary painter, who left a defining mark on European museography in 1990-2000 in that it transformed his museum into an institution fighting against museumfying and objectifying. Bernea aimed at representing in space different aspects and perspectives on a topic, and invited visitors themselves to give meaning to the space they pass through and to find personal answers to their questions. Bernea placed emphasis on feeling rather than knowing, so much that one fundamental feature of his vision was the absence of informative labels and of discourse based on labels. The freedom of Bernea's museography earned the institution in 1996 the title "European Museum of the Year." Bernea's vision was preserved to this day and embodies the museum's long-term strategy (Romanian Peasant Museum). The fact that the Romanian Peasant Museum maintains the same simplistic approach and chooses to ignore current trends in interpretation attracts the sympathy and appreciation of a wide audience, although there are visitors as well as specialists who have conflicting views on this approach.

In the last years, in an European context which encourages the multiculturalism and facilitates the access of foreign visitors more than before, Bernea's simplistic vision is perceived differently by the new public, a more sophisticated one. In 2013, Peasant Museum received the Certificate of Excellence from TripAdvisor, the biggest website of tourist promotion in the world, based on users' reviews (Muzeul Taranului Roman). According to the latest reviews in 2016, it is noticed a different perception between Romanian visitors and the foreigners. If the first ones can easily relate to the collection only through visual information, the others have difficulties in understanding what the objects presented represent, because of the lack of signage and informative 
labels. Though, all the positive reviews reinforce the value of the museum collection. "Lots of folk costumes from all around the country", "I love folklore. So if I want to have the sense, taste and smell of 'AT HOME', I use to visit both (Peasant Museum and Village Museum)", are just some of the reactions from the Romanian visitors(Trip Advisor). Though, many of them mistake Peasant Museum for Village Museum. For the foreigners, the experience is different. The main drawback in terms of presentation and interpretation is that the Peasant Museum is difficult to read, especially for them. Informative labels are used here and there, but they often contain information only in Romanian. Some of them thinks that the museum looks like a garage sale with random antiques in a massive, empty building, without knowing what is the meaning of what is displayed. Some others believe that there is a need of "refreshment" and of a newly perspective regarding the attitude towards the public, considering a disadvantage the fact that it is forbidden to take pictures inside the museum.

On the other hand, there are rooms which create atmosphere by context (such as the "School in the Countryside" room) and which can be easily interpreted and understood. One of the most popular room is the one named "Food". There, through a wood installation looking like a spiral, called "podina", it is presented the mystic circle of life and death and the importance of food, land and religion in the rural Romania. Visitors have to walk on it from the ground to the last level and to discover a variety of agricultural products. It is a combination between poetry and pure visual information, that help the visitor to connect with the rural space in an interactive and original way. But there are only few examples of spaces that encourage interaction.

Mostly, there are spaces where the exhibited objects are decontextualized and are present as such, without any information as to what they stand for - this is the case with the "Peasant Art" room. The fact that the museum is largely composed of symbols (Figure 1) and presents traditional rituals, thus combining life in the countryside with spirituality (Figure 2), creates the need to support visitors and to provide an interpretation so they can understand the topic addressed. This is the only way that a real connection between visitors and the space they are in can be created. On the other hand, the visitors cannot be provoked by something that they do not understand or that is unclear to them, and a museum's capacity to provoke is crucial to its competitiveness.

All in all, this traditional approach proved to be controversial, as long as it is not adapted to the nowadays needs. However, the Romanian Peasant Museum ranked second among the most visited museums in Bucharest in 2014, second only to the Antipa Museum. Its activity can be improved at several levels; its main weakness is the low efficiency in conveying the message, given that not all visitors choose audio guidance or resort to a guide's services. As regards its involvement in social life and handling of topics that will keep it actual, the Romanian Peasant Museum has tried and succeeded in assuming this role, in spite of the fact that it generated sympathy as well as confusion and attracted the discontent of a representative segment of the population. By establishing the "New Cinema of the Romanian Directors," the Museum managed to retain its freshness and to connect Romanian traditional culture to European values.

A different approach is attempted in the Memorial to the Victims of Communism and to the Resistance. It was preceded by the creation by writer 


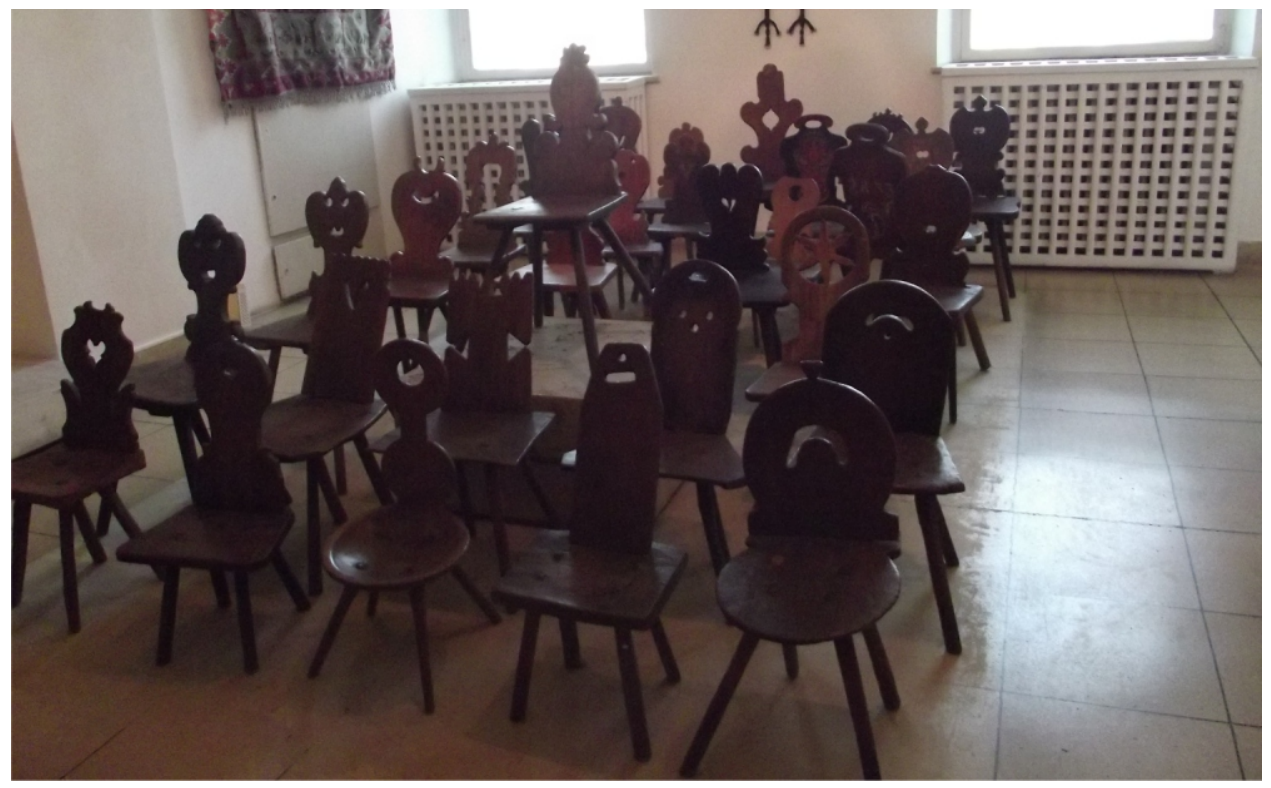

Figure 1. Symbol inside Peasant Museum

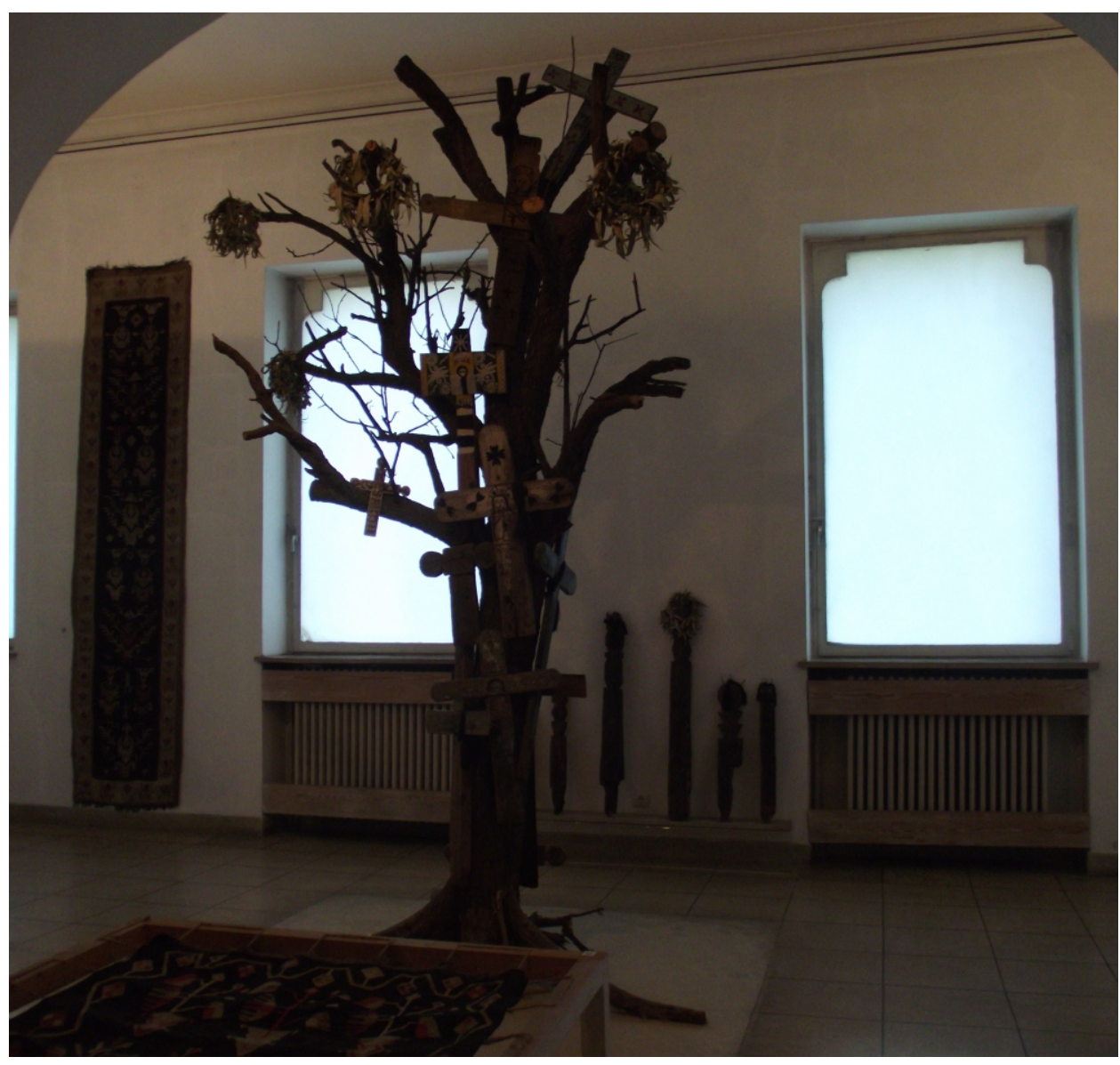

Figure 2. The cross/the tree of life room (Peasant Museum) 
Romulus Rusan of the International Centre for Studies into Communism, an institution that has been to this day documenting communist past. The establishment of the Sighet Memorial, following poetess Ana Blandiana's initiative, was a necessity after 1989, and stemmed from a desire to erase from collective memory the new man without memory, which Ceausescu wanted so ardently. It constitutes a valuable interface in terms of to the work carried out in the research centre located at the back, being is also an important space of identity and collective memory, as it is currently operating in the space of the former prison in Sighet. It was here where, during the communist era, an impressive number of political prisoners, ordinary people as well as important Romanian personalities, were incarcerated and died.

The museum is an incursion of the history of communism in Romania and in former communist countries of Central and Eastern Europe. From this point of view, given that Romania has no museums dedicated to communism, the Sighet Memorial —also known as the Memorial of Pain-, deals with the topic of communism from the victims' perspective and uses mainly two of Tilden's principles: it refers to a common past and it involves the visitors in the process of interpretation, while provoking them by means of the emotional significance typical of the place and by means of stories of the regime's victims. The ultimate goal of interpretation at Sighet is not only to inform about the common past, but also to bring before the public information which years ago was not accessible, precisely in order to learn from past mistakes and avoid the possibility that similar events may occur in the future. The main strength of the interpretation programme lies in the alternation of raw information and interpreted information. The first category includes interviews that visitors can listen on headphones or the use of diverse presentation methods, providing information tailored to each of them, whether they are audio techniques, as is the case with Room 18 - Collectivization Resistance and repression (Figure 3), photodocuments or other original documents on display.

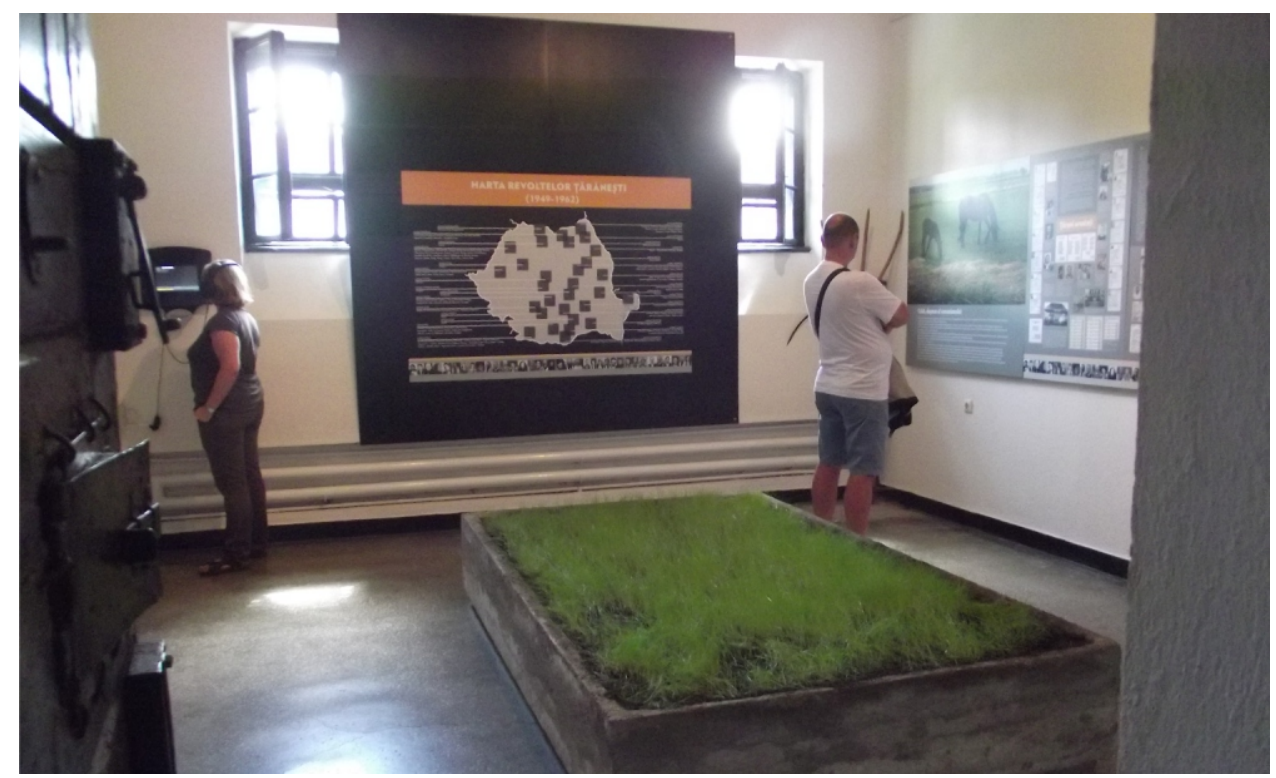

Figure 3. Room 18.Collectivization. Resistance and repression 


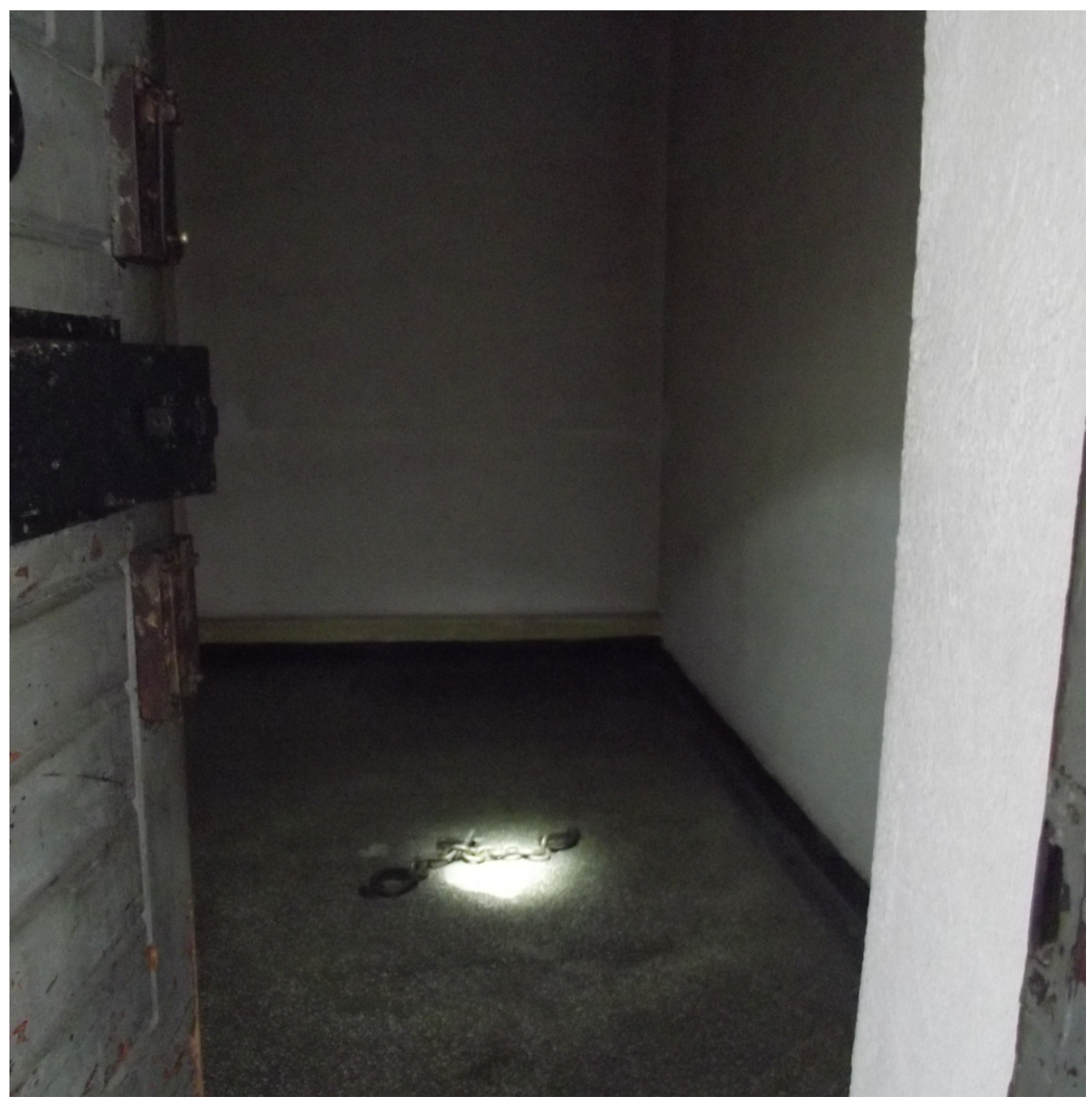

Figure 4. Room 9. Black Room

As regards the second category, information is interpreted or mentioned as such and contextualized, through various facilities existing in the space and which can be explored by visitors, as is the case with rooms such as Room 14 Securitate (secret service) from 1948 to 1989 or Room 75 - Demolitions in the 80 s.

There is a limit in interpretation that experts managed to grasp: spaces with high emotional significance do not require a broad interpretation, as they are places that create a state and speak for themselves. In the Memorial, such spaces are Rooms 9 and 37 - Black, famous punishment cells, where prisoners were abandoned when they failed to comply with the rules laid down by the administration (Figure 4).

The Memorial also includes cells of prominent Romanian personalities such as Room 9 - Cell where Prime Minister Iuliu Maniu (1873-1953) died and Room 73 - Cell where politician and historian Gheorghe I. Bratianu died. Unlike the Romanian Peasant Museum, interpretation was designed so that the visitor may experience and explore on his own, without requiring a guide, which prevents 
the formation of groups and congestions that alter the experience of other participants. There are audio guides and in each room there is a sheet which describes each space and possibilities of interaction with it. Considering the impressive amount of information and special significance of the place, the experience does not end abruptly: the visitor has the opportunity to go to the inner courtyard where there is a space for introspection and prayer. It was fitted out for casual visitors but especially for victims, relatives and people who at a certain point dealt with this topic.

In 2016, The Memorial of the Victims of Communism and of the Resistance received for the third year in a row a Trip Advisor Excellence Certificate based on users' reviews (Memorialul Victimelor Comunismului si al Rezistentei, 2016). In a different way, the reviews highlights mostly the quality and quantity of the information provided and the diversity in interpreting it. One of the most frequent words used by the foreigners are "accuracy", "strong emotion", "experience" or "information". Most of them believe that the impressive amount of information displayed complements very well the emotional impact that the place have on visitors, as a former prison (Trip Advisor). Because there are no guided tours, one thing that misses is the signage in other languages that Romanian. Tough, most of the visitors consider that the materials in English and other languages existing at the entrance of each room are efficient. For the Romanians, the place is full of nostalgia and it carries an important identity. Regarding the relevance of the story presented, as opposed to the Peasant Museum, the review from both foreigners and Romanians are more homogenous, because of the holistic approach regarding communism which makes it easier to connect with.

\section{Conclusions}

In Romania, despite the fact that tourism interpretation is still a vague concept, associated especially with the tasks of a guide, there is a need for museums to keep up with the institutions representing the creative industry, that propose an approach clearly oriented towards manifesto culture, namely culture that sends a strong message and provokes, focusing in great detail on the public it addresses. Museums must integrate in this new wave of Western inspiration; otherwise, they run the risk of failing to assume their role of social and cultural pillars of society. General guidelines of presentation and interpretation are influenced by two important factors: the first one is the museum's capacity to promote its activity and, implicitly, to attract funds; the second is related to the educational dimension and programmes carried out by museums for different age groups.

Whereas in the last decades Romanian museums have survived only because of the importance of the collections they hosted, currently joint efforts converge. A catalyst and a point of reference in this respect were important cultural events, whose main benefit was that they brought together the museum community and offered museums the opportunity to express themselves in a personal manner, ensuring their visibility. The event with the greatest impact from this point of view is the Museums Night, held in Romania since 2005. The organisation of 
this event, which takes place in 30 European countries, is an attempt of the National Network of Romanian Museums to become a platform as well as an opportunity to relaunch the entire museum field and gradually integrate it in the creative industries. The process is still in its infancy, so museums do nothing more than participate, so their motivation and ability to express themselves at an appropriate level is not visible. In Romanian museology, classical approach still prevails, as work is carried out by teacher trained specialists and less by the creative representatives of performing arts or of other participatory events. In this respect, knowledge related strictly to the entertainment function is poorly appropriated.

An analytical perspective of the museums' activity and manner of presentation suggests that the ideas which made Tilden famous are known to a limited extent or not at all, although they could be used as a starting point in the development of Romanian heritage interpretation. There is no coherence or consistency in the expression, that is why the programmes offered revolve around the idea of object and collection. There is an obsession as well as a culture of turning museum objects into monuments, which limits the possibilities of interpreting them. Tilden's 6 principles are absent from Romanian museums precisely because, by their very nature, they encourage dialogue and engagement, provoke and intrigue, which is different from what museums are prepared to offer at the moment. This happens also because assuming their social role involves equally a change in register as well as facing criticism, and many cultural institutions are not ready for such a move.

In this situation, not knowing what a museum should stand for and missing the tools to make it attractive for the visitors, creates ambiguity inside the community. Even the concept of museum is challenged in the attempt to make the transition from providing information to interpreting it, from instruction to provocation and from individual to collective, as Tilde proposed years ago.

\section{References}

Beck, L \& Cable, TT 2011, The Gifts of Interpretation: Fifteen Guiding Principles for Interpreting Nature and Culture, Sagamore Pub.

Chenari, M 2009 'Hermeneutics and theory of mind', Phenomenology and the Cognitive Sciences, vol. 8, pp. 17-31.

Coren, S 2003, 'Sensation and Perception', Handbook of Psychology, Wiley, J \& Sons, Inc., Gadamer, HG(ed.), Text and Interpretation, Phainomena, p. 70.

Gallagher, S 2004, 'Hermeneutics and the cognitive sciences', Journal of Consciousness Studies, vol. 11, pp. 162-174.

Grisham, C 2014, 5 Names for Museum Educators. American Association for State and Local History (AASLH), http://blogs.aaslh.org/5-names-for-museum-educators/, last accessed: May 02, 2016.

Ham, SH 2013, Interpretation: Making a difference on purpose, Fulcrum publishing.

Heshmat, S 2015, 10 Common Myths About Emotions (and Why They're Wrong), Psychology Today, Sussex Publishers LLC, United Kingdom, Sussex.

Ludwig, T 2003, Basic Interpretive Skills, Germany. 
Mccall, V \& Gray, C 2013, 'Museums and the 'new museology': theory, practice and organisational change', Museum Management and Curatorship, vol. 29, pp. 19-35.

Memorialul Victimelor Comunismului si al Rezistentei, 2016, Certificat de excelenta 2016 de la TripAdvisor pentru Memorialul Sighet, www.memorialsighet.ro/certificat-deexcelenta-2016-de-la-tripadvisor-pentru-memorialul-sighet/ last accessed: May 23, 2016.

Muzeul Taranului Român, 2013, Muzeul National al Taranului Român primeste certificatul de excelenta Tripadvisor pe anul 2013, www.muzeultaranuluiroman.ro/acasa/certificatulde-excelenta-tripadvisor-ro.html, last accessed: May 25, 2016.

Oxford Dictionaries, 2016, Definition of interpreter in English, Oxford University Press, www.oxforddictionaries.com/definition/english/interpreter, last accessed: April 18, 2016.

Rotila, V 2004, 'Perceptie si aperceptie în filosofia lui Maurice Merleau-Ponty (Perception and aperception in Maurice Merleau-Ponty's philosophy)', Analele Universitatii Dunarea de Jos.

Staiff, R 2014, Re-imagining Heritage Interpretation: Enchanting the Past-Future, Ashgate Publishing, Limited.

Tilden, F 1967, Interpreting Our Heritage, University of North Carolina Press.

TRIP ADVISOR, Memorial of the Victims of Communism and of the Resistance, www.tripadvisor.com/Attraction_Review-g608955-d622822-ReviewsMemorial_of_the_Victims_of_Communism_and_of_the_ResistanceSighetu_Marmatiei_Maram.html, last accessed: May 25, 2016.

TRIP ADVISOR. Peasant Museum (Muzeul Taranului Roman),

www.tripadvisor.com/Attraction_Review-g294458-d487989-Reviewsor10Peasant_Museum_Muzeul_Taranului_Roman-Bucharest.html\#REVIEWS, last accessed: May 25, 2016.

Tröndle, M, Wintzerith, S, Wäspe, R \& Tschacher, W 2012, 'A museum for the twenty-first century: the influence of 'sociality' on art reception in museum space', Museum Management and Curatorship, vol. 27, pp. 461-486.

Urry, J \& Larsen, J 2011, The Tourist Gaze 3.0, SAGE Publications. 